\title{
Article \\ Comparative Efficacy of Levetiracetam for Epilepsy in School-Aged Children with Intellectual Disability and Normal Intelligence
}

\author{
Ja Un Moon ${ }^{1,2}$ and Ji Yoon Han ${ }^{1,3, * \mathbb{C}}$ \\ 1 Department of Pediatrics, College of Medicine, The Catholic University of Korea, Seoul 06591, Korea; \\ gonicky@naver.com \\ 2 Department of Pediatrics, Seoul St. Mary's Hospital, The Catholic University of Korea, Seoul 06591, Korea \\ 3 Department of Pediatrics, Daejeon St. Mary's Hospital, The Catholic University of Korea, \\ Daejeon 34943, Korea \\ * Correspondence: han024@catholic.ac.kr; Tel.: +82-42-220-9246
}

Citation: Moon, J.U.; Han, J.Y.

Comparative Efficacy of

Levetiracetam for Epilepsy in

School-Aged Children with

Intellectual Disability and Normal

Intelligence. Brain Sci. 2021, 11, 1452.

https://doi.org/10.3390/

brainsci11111452

Academic Editor: Simona Lattanzi

Received: 28 September 2021

Accepted: 29 October 2021

Published: 31 October 2021

Publisher's Note: MDPI stays neutral with regard to jurisdictional claims in published maps and institutional affiliations.

Copyright: (C) 2021 by the authors. Licensee MDPI, Basel, Switzerland. This article is an open access article distributed under the terms and conditions of the Creative Commons Attribution (CC BY) license (https:// creativecommons.org/licenses/by/ $4.0 /)$.

\begin{abstract}
Choosing optimal anti-seizure medication (ASM) is very important in pediatric patients with epilepsy who attend school, especially children with an intellectual disability (ID). Levetiracetam (LEV) has proven to be an effective, safe, generally well-tolerated, broad-spectrum ASM in children. In the context of increasing use of LEV in school-aged children with epilepsy and ID, we evaluate relevant clinical data, including efficacy, safety, and tolerability in children with epilepsy and an intellectual disability (ID) or normal intelligence (NI). We performed a retrospective chart review of children and included 298 pediatric patients with epilepsy who were treated with LEV with NI (147) and ID (151). After 6 months, $96 \%$ of NI and $83 \%$ of ID subjects had a seizure reduction rate greater than $50 \%$ ( $p=0.031)$. The tolerability of LEV was generally good, with $75 \%$ retention rates at 2 years in both groups and only minor side effects (under 15\%). The retention rates of patients with NI and ID were $76 \%$ and $74 \%$, respectively ( $p=0.597)$. Thus, LEV showed considerable efficacy with minimal side effects and high retention rates and is an easily maintained and safe treatment option for pediatric epilepsy with ID. However, better-designed research studies are needed to clearly elucidate the efficacy and safety of LEV in children with epilepsy and ID.
\end{abstract}

Keywords: levetiracetam; anti-seizure medications; intellectual disability; epilepsy; children; efficacy; adverse reaction; retention rate; monotherapy; polytherapy

\section{Introduction}

Epilepsy is one of the most common major neurological diseases in the pediatric population, affecting 4-10 per 1000 children [1]. Neurodevelopmental disorders, including developmental delay (DD) or intellectual disability (ID), are common in pediatric patients with epilepsy and are likely to increase the risk of seizures [2]. The prevalence of epilepsy in children with ID ranges from 30 to $50 \%$, which is higher than in the general population and tends to be poorly controlled [3]. In addition, children with ID are more likely to develop intractable epilepsies and might experience further intellectual deterioration resulting from inappropriate use of anti-seizure medication (ASM). However, some children with ID experienced improvement of cognitive ability after seizure control [2]. Given these factors, treatment strategies should focus on controlling seizures and managing behavioral and cognitive comorbidities. Unfortunately, the treatment of choice for epilepsy in children with DD/ID has not been well-established, and guidelines for ASM for children with ID are not different from those of children with solitary epilepsy. Therefore, more evidence-based information on treatment options is needed to address the insufficiency of current treatment strategies.

Levetiracetam (LEV) has been proven to be an effective, safe, generally well-tolerated, and broad-spectrum ASM in children with focal or generalized epilepsy [4]. LEV has 
favorable benefits that make it effective and suitable for children with epilepsy: optimal bioavailability, no interactions with other ASMs, low protein binding, and multiple drug formulations [5]. In addition, LEV is important for children during development and learning periods as it positively affects behavior and cognitive functions [6]. However, despite the increasing use of LEV in school-aged children with epilepsy and ID, data on the efficacy and safety of LEV for such children remain insufficient. Therefore, this study aims to evaluate the efficacy, tolerability, and safety of LEV in school-aged pediatric patients with epilepsy and ID by comparing this population to children with normal intelligence (NI).

\section{Methods}

We performed a retrospective chart review of children aged 6-18 years with epilepsy and ID who visited The Catholic University of Korea Seoul St. Mary's Hospital between January 2010 and May 2019. Children were eligible for inclusion if they were treated with LEV and followed for more than 2 years. One pediatric neurologist reviewed the medical charts of all patients and extracted information including demographics (age, gender), seizure type, clinical findings, brain magnetic resonance images (MRI), biochemical results, and concomitant ASM. The mean LEV dosage, duration of LEV treatment, and dropout rate of LEV were assessed after 6, 12, and 24 months. Outcomes of seizures following LEV treatment were assessed in the first 6 months and defined based on seizure frequency or clinical manifestations as no change or $<50 \%$ reduction in seizure frequency, $50-99 \%$ reduction in seizure frequency, and seizure-free. To determine the sole effect of LEV in polytherapy, the frequency of seizures of each group before and after LEV addition was also evaluated. Safety assessments, including adverse reactions, laboratory parameters, vital signs, physical and neurological examinations, and electrocardiography, were conducted over 6, 12, and 24 months. The definition of epilepsy and the classification of seizures were determined according to categories proposed by the International League Against Epilepsy (ILAE) in 2014 and 2017, respectively [7,8]. Intelligence quotient (IQ) of 70 or below with at least two behaviors related to adaptive functioning deficits manifesting before age 18 was defined as ID. The levels of severity of ID were classified into mild (IQ of 50-69), moderate (35-49), severe (20-34), and profound $(<20)$ by the Wechsler intelligence test or Wechsler Preschool and Primary Scale of Intelligence. We performed all statistical analyses using SSPS software version 24.0 (IBM Corp., Armonk, NY, USA), and continuous variables were presented as means and standard deviation (SD). The relationship between the before and after the addition of LEV in polytherapy was evaluated using a paired t-test. We compared categorical variables using Chi-square/Fisher's exact test and assessed continuous variables using Kruskal-Wallis test to analyze significant differences between two groups (NI and ID). We considered probability values less than 0.05 as statistically significant. This study was approved by the Institutional Review Board of The Catholic University of Korea (KC21RASI0633).

\section{Results}

\subsection{Demographics and Clinical Characteristics}

A total of 298 pediatric patients with epilepsy who were treated with LEV was included in this study. The demographic and clinical characteristics of the patients are shown in Table 1. Among the 298 patients, 147 (70 females, 77 males) had NI, and 151 (71 females, 80 males) had ID. Of 151 patients with ID, 74 (49\%) had mild ID, $54(36 \%)$ had moderate ID, and $23(15 \%)$ had severe to profound ID. The mean ages of patients with NI and ID were 12.3 and 12.0 years, respectively. The mean age at onset of seizures in NI was 5.5 years (range: 1 month-15 years) and in ID was 4.5 years (range: 1 week-15 years). In patients with NI, $28(19 \%)$ had localized seizures, and $83(56 \%)$ had generalized seizures, while the rest $(n=36,25 \%)$ had both. 
Table 1. Demographic and clinical characteristics.

\begin{tabular}{|c|c|c|c|}
\hline Variables & $\begin{array}{c}\text { Normal Intelligence } \\
n=147(49 \%)\end{array}$ & $\begin{array}{c}\text { Intellectual Disability } \\
n=151(51 \%)\end{array}$ & $p$ Value \\
\hline $\begin{array}{l}\text { Gender, } n(\%) \\
\text { Female: Male }\end{array}$ & 70 (48\%): $77(52 \%)$ & $71(47 \%): 80(53 \%)$ & 0.918 \\
\hline Mean age, years $( \pm S D)$ & $12.3( \pm 4.6)$ & $12.0( \pm 4.7)$ & 0.422 \\
\hline Mean age at seizure onset, years $( \pm S D)$ & $5.5( \pm 4.6)$ & $4.5( \pm 4.3)$ & 0.232 \\
\hline $\begin{array}{c}\text { Seizure type, } n(\%) \\
\text { Localized } \\
\text { Generalized } \\
\text { Mixed/Unclassified }\end{array}$ & $\begin{array}{l}28(19 \%) \\
83(56 \%) \\
36(25 \%)\end{array}$ & $\begin{array}{l}17(11 \%) \\
81(54 \%) \\
53(35 \%)\end{array}$ & 0.390 \\
\hline $\begin{array}{c}\text { Etiology of epilepsy, } n(\%) \\
\text { Cerebral infection } \\
\text { Perinatal problems } \\
\text { Structural malformation } \\
\text { Metabolic abnormality } \\
\text { Vascular abnormality } \\
\text { Tumor } \\
\text { Trauma } \\
\text { Genetic } \\
\text { Idiopathic/Unknown }\end{array}$ & $\begin{array}{c}4(2.5 \%) \\
7(5 \%) \\
6(4 \%) \\
3(2 \%) \\
6(4 \%) \\
4(2.5 \%) \\
3(2 \%) \\
10(7 \%) \\
104(71 \%)\end{array}$ & $\begin{array}{c}4(2.5 \%) \\
30(20 \%) \\
43(29 \%) \\
5(3.5 \%) \\
8(5 \%) \\
4(2.5 \%) \\
5(3.5 \%) \\
12(8 \%) \\
40(26 \%)\end{array}$ & 0.074 \\
\hline $\begin{array}{c}\text { Brain MRI, } n(\%) \\
\text { Normal } \\
\text { Abnormal } \\
\text { Missing data }\end{array}$ & $\begin{array}{c}101(69 \%) \\
44(30 \%) \\
2(1 \%)\end{array}$ & $\begin{array}{c}47(31 \%) \\
99(66 \%) \\
5(3 \%)\end{array}$ & 0.044 \\
\hline $\begin{array}{c}\text { Mean maximal dosage of LEV } \\
(\mathrm{mg} / \mathrm{kg} / \text { day }) \\
\text { Monotherapy, } n(\%) \\
\text { Polytherapy, } n(\%)\end{array}$ & $\begin{array}{c}33.0 \\
51(35 \%) \\
96(65 \%)\end{array}$ & $\begin{array}{c}33.5 \\
36(24 \%) \\
115(76 \%)\end{array}$ & $\begin{array}{l}0.517 \\
0.047\end{array}$ \\
\hline $\begin{array}{c}\text { Number of concomitant ASMs } \\
1 \\
2 \\
\geq 3\end{array}$ & $\begin{array}{c}68 \\
21 \\
7\end{array}$ & $\begin{array}{l}50 \\
36 \\
29\end{array}$ & \\
\hline
\end{tabular}

MRI, magnetic resonance image; LEV, levetiracetam; ASM, anti-seizure medication.

Among ID patients, 17 (11\%) had localized seizures, 81 (54\%) had generalized seizures, and $53(35 \%)$ had both types. Most patients with NI had unknown causes of epilepsy $(n=104,71 \%)$ followed by genetic causes $(n=10,7 \%)$ such as Prader-Willi syndrome, Fragile $\mathrm{X}$ syndrome, or microdeletion/duplication, but not all patients had undergone genetic testing. Structural malformation (e.g., lissencephaly, cortical dysplasia) and perinatal problems (e.g., hypoxic insult) accounted for a large proportion of the causes of epilepsy in ID patients ( $n=43,29 \%$ and $n=30,20 \%$, respectively) $(p=0.044)$. There was no statistically significant difference between the two groups in gender, mean age, mean age of seizure onset, seizure type, or etiology ( $p=0.918,0.422,0.232,0.390$, and 0.074 , respectively). Brain MRI analyses showed abnormalities to be significantly more common in ID patients ( $n=99$, $66 \%)$ compared to patients with NI $(n=44,30 \%)(p<0.044)$. The mean dosage of LEV per day was $33 \mathrm{mg} / \mathrm{kg}$ in both groups, ranging from $10 \mathrm{mg} / \mathrm{kg}$ to $60 \mathrm{mg} / \mathrm{kg}(p=0.517)$. Significantly more patients with NI $(n=51,35 \%)$ had received LEV as a single treatment (monotherapy) compared to those with ID $(n=36,24 \%)$, while more patients with ID ( $n=115,76 \%$ ) received LEV as a combined treatment with other ASMs (polytherapy) than those with NI $(n=96,65 \%)(p=0.047)$. Among the polytherapy group, patients with ID required more ASMs in addition to LEV treatment: one $(n=68,70 \%)$, two $(n=21,22 \%)$, or more than two $(n=7,8 \%)$ in patients with NI, whereas patients with ID showed one $(n=50,44 \%)$, two $(n=36,31 \%)$, and more than two $(n=29,25 \%)$ additional ASMs. 


\subsection{Adverse Effects}

Overall, there were no significant differences in the adverse reactions between patients with NI and ID ( $p=0.397)$ (Table 2$)$ or between monotherapy and polytherapy $(p=0.411)$. A total of 35 (12\%) of all patients (20 with NI, 15 with ID) experienced adverse reactions, and none had life-threatening events. Most patients experienced adverse reactions within three months of beginning LEV treatment, resulting in immediate treatment interruption in some cases. However, no such differences were associated with adverse reactions and a mean dosage of LEV $(p=0.377)$ in all patients. The most frequently observed adverse reactions were sedation $(n=17,49 \%)$, including fatigue and somnolence, followed by neuropsychiatric events $(n=8,23 \%)$, including aggression/irritability and depression, headaches $(n=5,14 \%)$, dizziness $(n=4,11 \%)$, and loss of appetite $(n=1,3 \%)$. The overall neuropsychiatric events between patients with NI and with ID were not significantly different.

Table 2. Efficacy, safety, and tolerability of levetiracetam.

\begin{tabular}{cccc}
\hline Variables & $\begin{array}{c}\text { Normal Intelligence } \\
(\boldsymbol{n}=\mathbf{1 4 7})\end{array}$ & $\begin{array}{c}\text { Intellectual } \\
\text { Disability } \\
(\boldsymbol{n = 1 5 1 )}\end{array}$ & $p$ Value \\
\hline $\begin{array}{c}\text { Response to LEV (a) } \\
\text { No change or }<50 \%\end{array}$ & $5(4 \%)$ & $25(17 \%)$ & 0.031 \\
$50-99 \%$ & $87(59 \%)$ & $108(71 \%)$ & \\
Seizure-free & $55(37 \%)$ & $18(12 \%)$ & 0.397 \\
Adverse event & $127(86 \%)$ & $136(90 \%)$ & \\
No & $20(14 \%)$ & $15(10 \%)$ & 0.612 \\
Yes & $128(87 \%)$ & $129(84 \%)$ & \\
Retention rate $(\%)$ & $120(81 \%)$ & $118(78 \%)$ & \\
$<6$ months & $112(76 \%)$ & $111(74 \%)$ & \\
12 months & & & \\
$>24$ months & &
\end{tabular}

LEV, levetiracetam; (a) based on the reduction in seizure frequency (\%).

\subsection{Response Rate}

The number of individuals seizure-free within 6 months among the patients with NI $(n=55,37 \%)$ was significantly higher than in those with ID $(n=18,12 \%)$ (Table $1, p=0.031)$. Of the 147 patients with NI, a 50-99\% reduction in seizure frequency was observed in $59 \%(n=87)$, and no change or $<50 \%$ reduction in seizure frequency was observed in $4 \%$ $(n=5)$, while $71 \%$ of patients with ID showed a $50-99 \%$ reduction in seizure frequency $(n=108)$, leaving $17 \%$ as no change or $<50 \%$ reduction in seizure frequency $(n=25)$. There was no significant difference between patients in monotherapy or polytherapy $(p=0.271)$ (Figure 1A).

Among those who received LEV as a monotherapy, patients with NI $(n=30,59 \%)$ were more likely to be seizure-free than patients with ID $(n=6,17 \%)$ (Figure 1B, $p=0.011$ ) In polytherapy, the addition of LEV was significantly effective compared to before the addition of LEV in both groups of children $(p=0.033$, Figure 1D and $p=0.041$, Figure 1E, respectively). However, there was no significant difference in response rates between NI and ID who received LEV as a polytherapy (Figure $1 C, p=0.411$ ). Thus, LEV was more effective in patients with NI, especially those who received LEV as a single therapy. 


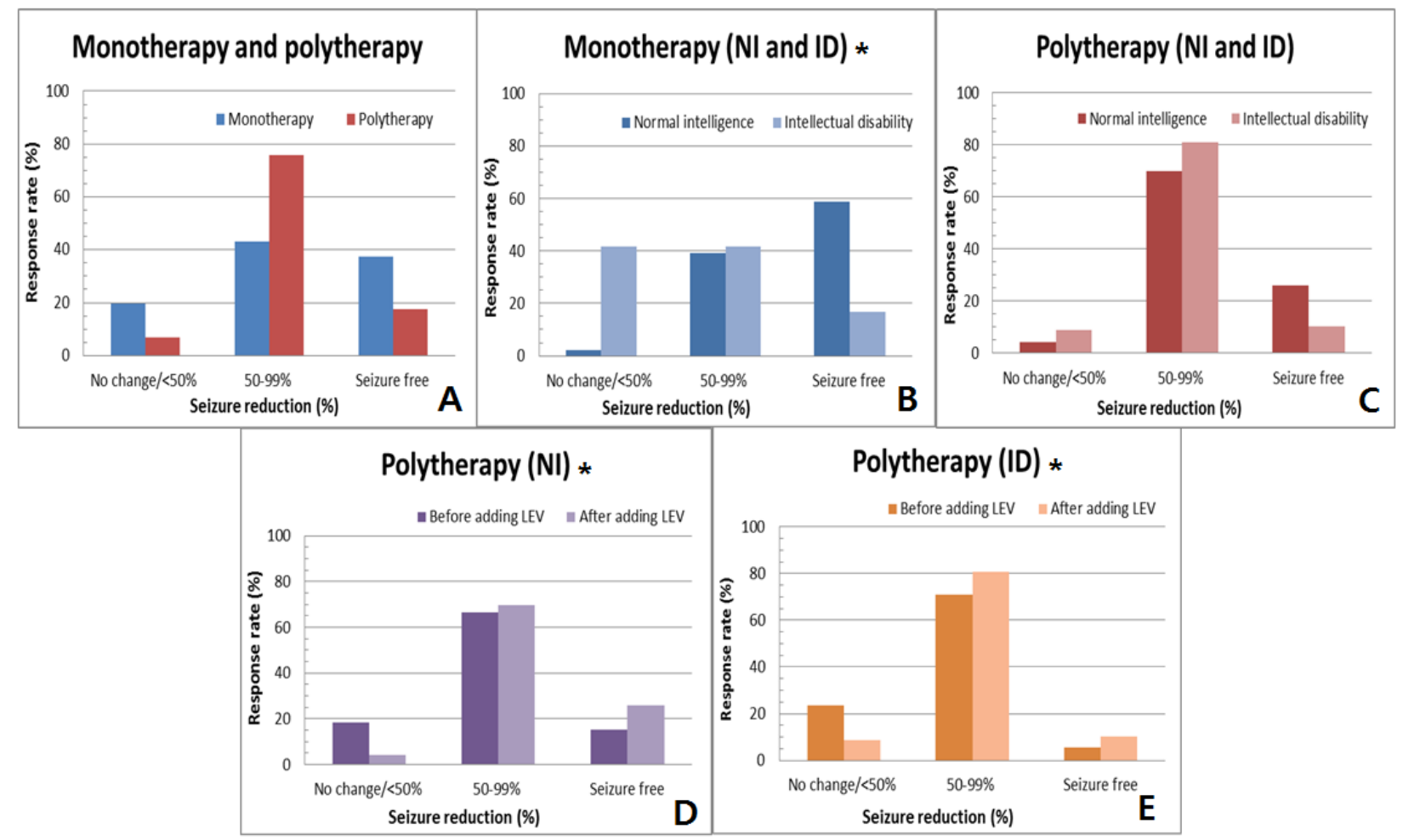

Figure 1. Efficacy after 6 months receiving LEV described in (A-C). (A) Comparing the efficacy of monotherapy and polytherapy, there was no significant difference in seizure reduction between two groups. (B) Comparing the efficacy of patients with NI and ID in monotherapy, patients with NI showed higher response rate of being seizure-free than those with ID (Chi-square test, $p=0.011$ ). (C) Comparing the efficacy of patients with NI and ID in polytherapy, there was no significant difference of response rates between two groups. (D,E) Response rate of seizure reduction before and after addition of LEV in polytherapy. Both NI and ID groups were significantly affected by the addition of LEV (paired $t$-test, $p=0.033, p=0.041$, respectively). An asterisk indicates the statistically significant difference between the two groups; LEV, levetiracetam; NI, normal intelligence; ID, intellectual disability.

\subsection{Retention Rate}

The retention rates for LEV treatment after 6 and 12 months were $87 \%$ and $81 \%$, respectively, in patients with NI, and $84 \%$ and $78 \%$, respectively, in patients with ID (Figure 2A). Patients with NI and ID remained on LEV treatment at similar rates after 24 months $(76 \%$ and $74 \%$, respectively; $p=0.612$ ). Thirty-five patients with NI and 40 patients with ID dropped out of the treatment. The most common reasons for discontinuation of LEV treatment in patients with NI and ID were lack of efficacy (11\% and $13 \%$, respectively), followed by intolerable adverse reactions ( $7 \%$ and $8 \%$, respectively). Although there was a trend that patients with NI in the monotherapy group and patients with ID in the polytherapy group showed longer retention times, no statistically significant differences were observed (monotherapy: 76\% with NI and 75\% with ID; polytherapy: 76\% with NI and 73\% with ID; Figure 2B, $p=0511$ ). 


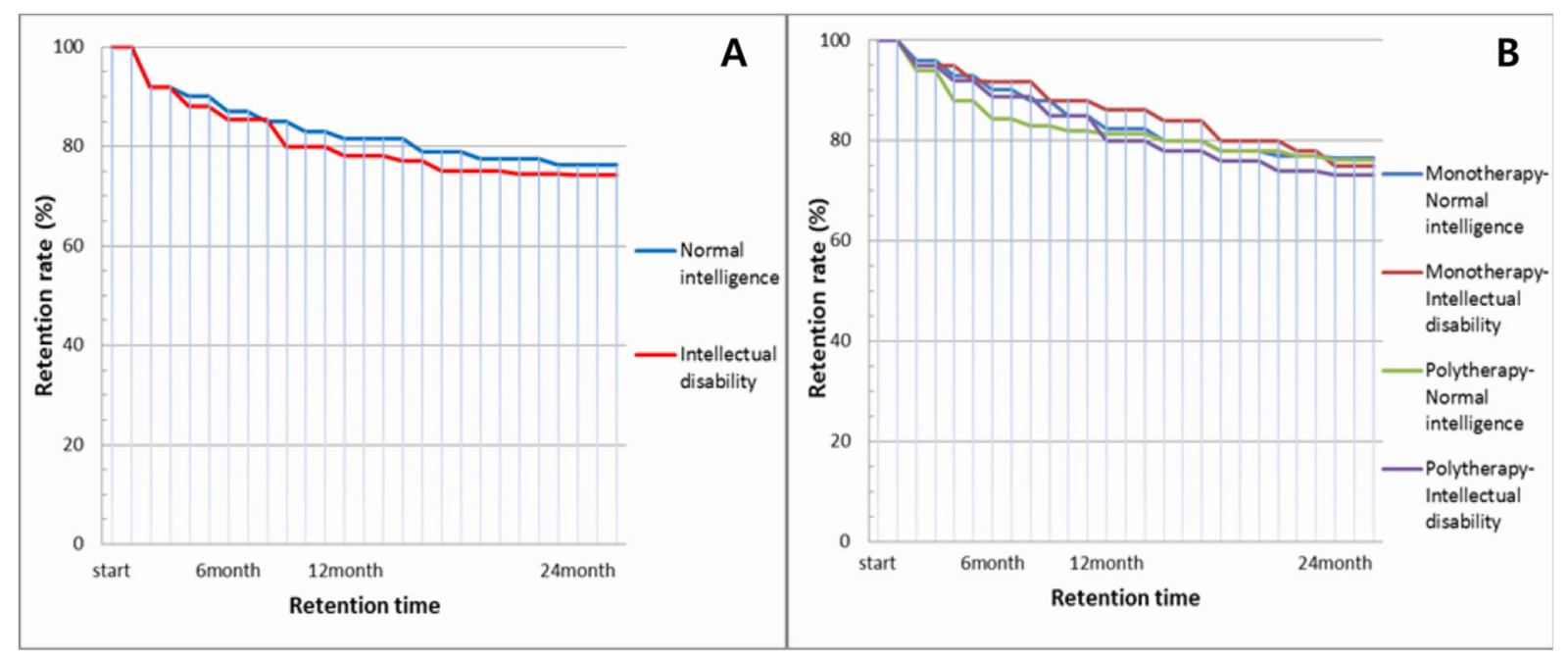

Figure 2. Retention rates at 6,12, and 24 months after treatment with levetiracetam. (A) Patients with normal intelligence and intellectual disability. ( $p=0.612)$. (B) Patients with normal intelligence and intellectual disability in monotherapy and polytherapy $(p=0.511)$.

\section{Discussion}

ID and epilepsy appear to share common pathogenic mechanisms [9]. The prevalence of epilepsy in patients with ID is about $22 \%$ and increases with the severity of ID [10]. Therefore, it is important to ascertain the optimal ASM for pediatric patients to prevent avoidable impairment, especially in this vulnerable group. Children with neurodevelopmental disorders have higher recurrence rates after a single unprovoked seizure than those with NI [1]. In addition, prolonged or repetitive seizures and status epilepticus are more common in children with multiple disabilities and are difficult to treat [11]. Vice versa, clusters of seizures can increase the severity of the neurodevelopmental disability. Forsgren's study reported that children with ID tend to have refractory seizures and are more likely to need polytherapy [12]. Likewise, in our study, $76 \%$ of patients with ID required treatment with more than one ASM, a higher percentage than among patients with NI (65\%), suggesting that children with ID are more likely to develop ASM resistance.

Behavioral and cognitive problems can significantly impact the quality of life of children with epilepsy and can be obstacles to ASM tolerability [13]. However, certain ASMs have negative effects on cognition and bring out behavioral problems. For example, cognitive impairment can be caused by long-term use of phenobarbital, and somnolence can be caused by phenytoin [14]. Therefore, these adverse reactions to ASMs must be considered in treatment decision-making, especially for children with neurodevelopmental disorders and children who need to acquire new academic skills [15].

Adverse behavioral effects in children associated with LEV treatment affect 15-38.5\% of patients with NI and more in patients with ID [16-21]. The rate of adverse reactions in this study was $14 \%$ and $10 \%$ in groups of NI and ID, respectively. As opposed to previous reports, these adverse reaction rates could be contributed to some minor side effects, including dizziness and mild fatigue, which might not have been noted in children with ID due to communication problems. Somnolence and fatigue, the most common side effects in both groups in this study, were considered minor and manageable effects and rarely led to discontinuation of LEV treatment. Neuropsychiatric adverse events, mostly irritability, hyperactivity, and aggression, were the second most frequent adverse effects in both groups, and all of these patients discontinued LEV treatment. However, children who had to discontinue LEV due to those effects comprised less than $8 \%$ of each group.

ASM that affects neurocognitive function should be avoided in school-aged children engaging in learning and skill acquisition. Although Levisohn et al. demonstrated through neurocognitive testing in children that memory and attention in children who received 
LEV were not significantly different from those in children who did not [6], another study showed that cognitive functions including attention, executive ability, and abstract and directional score improved after treatment with LEV [22]. Likewise, the International League Against Epilepsy (ILAE) reported that LEV could positively affect mood and cognitive functions [23]. We also have not found a noticeable decline of cognition in association with LEV treatment, and we anticipate that LEV would have less significant impacts on existing cognitive function, but additional studies related to cognitive functions are needed to confirm our hypothesis

Previous reports have suggested that even for refractory epilepsy patients, LEV had a favorable outcome and tolerable side effects [24]. LEV as an add-on treatment in pediatric patients has shown over a $50 \%$ seizure reduction in $20-60 \%$ of patients $[4,25]$, and 20 $46 \%$ of patients achieved seizure-freedom in three prospective open-label studies [26-28]. Although Brodtkorb, E. et al. found no significant difference in the efficacy of LEV between patients with or without ID [24], the seizure-freedom in patients with ID was lower than in the general population in some studies [29]. In our study, LEV appeared to be more effective in patients with NI since the response rate for seizure-free was greater in these patients $(37 \%)$, whereas among those with ID, only $12 \%$ became seizure-free $(p=0.031)$. In a similar vein, more patients with ID $(17 \%)$ had no change or a $<50 \%$ reduction in seizure frequency than those with NI (4\%).

Our results indicate that the tolerability of LEV is generally good, constituting about $75 \%$ of retention rates at 2 years in both groups and only minor side effects. The retention rates of patients with NI and ID were $76 \%$ and $74 \%$, respectively, higher than other studies reporting retention rates of $47-72 \%$ [30]. This discrepancy might result from differences in the patient populations investigated. Throughout the retention time, side effects accounted for only a small portion of the reasons for the discontinuation of LEV in both groups. Thus, LEV can be a well-tolerated and safe ASM option in school-aged childhood epilepsy with ID. Since genetic alternations play an important role in epileptogenesis and neurogenesis [31], genetic testing is becoming increasingly crucial in patients with poor seizure control, other neurodevelopmental or neurological symptoms, or a strong family history of epilepsy [32] for a genetic epilepsy diagnosis. For instance, individuals with a clinical diagnosis of Dravet syndrome are likely to have a variant in a gene called SCN1A, and sodium-channel blockers should be avoided for treatment. Although several studies demonstrated that LEV showed effectiveness on epilepsy with genetic alteration (e.g., CACNA1 and STXBP1 mutation) [33,34], studies based on the efficacy of LEV as a treatment for epilepsy with genetic alterations are very scarce. Only a small number of children underwent genetic tests in this study; therefore, further extensive research efforts are required to identify the therapeutic effect of LEV associated with genetic abnormalities. The main limitations of this study were its retrospective collection of data from medical charts, small sample of pediatric patients, and short length of follow-up observations during LEV treatment. Further prospective studies using larger cohorts are needed to establish a standard treatment protocol for children with epilepsy and ID. Since our results of the response rate to LEV were assessed as three categorical values, we consider that these categorical values might not represent the actual meaning of original continuous values and might have a risk of reducing statistical power. To instill confidence in the use of LEV, well-designed, double-blind, randomized controlled trials are needed to estimate the efficacy, adverse reactions, and tolerability of LEV in children with epilepsy and ID.

\section{Conclusions}

In pediatric epilepsy with ID, especially in school-age children, choosing the appropriate ASM is an unavoidable and important factor to protect against deterioration of neurodevelopment. The goal of ASM in children with epilepsy and ID is complete control of seizures and a positive impact on cognitive function without side effects. In this study, about $83 \%$ of children with ID showed $\geq 50 \%$ of seizure reduction, and $74 \%$ of them showed 2 years of retention rate without serious adverse reactions, confirming that LEV could be 
effective, well-maintained, and safe not only for the general population but also for such vulnerable children. However, the limited information derived due to the small sample included in this study suggests that more data on the effectiveness and practical utility of LEV based on controlled studies among children with ID and epilepsy are needed.

Author Contributions: Conceptualization, J.Y.H. and J.U.M.; methodology, J.Y.H.; formal analysis, J.U.M.; writing—original draft preparation, J.Y.H.; writing J.U.M. and J.Y.H.; supervision, J.Y.H. All authors have read and agreed to the published version of the manuscript.

Funding: This work was supported by the National Research Foundation of Korea (NRF) grant funded by the Korean Government (MSIT; 2021R1F1A1063568).

Institutional Review Board Statement: The study was conducted according to the guidelines of the Declaration of Helsinki and approved by the Institutional Review Board of The Catholic University of Korea (approval number: KC21RASI0633; date of approval: 17 May 2021).

Informed Consent Statement: The requirement for patient consent was waived by the Institutional Review Board of The Catholic University of Korea due to the retrospective nature of this study.

Data Availability Statement: The data presented in this study are available on request from the corresponding author. The data are not publicly available due to national regulations.

Acknowledgments: The authors are grateful to College of Medicine of The Catholic University of Korea for their assistance in performing the present study.

Conflicts of Interest: The authors declare that they have no competing interests.

\section{References}

1. Berg, A.T. Risk of recurrence after a first unprovoked seizure. Epilepsia 2008, 49, 13-18. [CrossRef] [PubMed]

2. Coulter, D.L. Comprehensive management of epilepsy in persons with mental retardation. Epilepsia 1997, 38, S24-S31. [CrossRef]

3. Berg, A.T.; Langfitt, J.T.; Testa, F.M.; Levy, S.R.; DiMario, F.; Westerveld, M.; Kulas, J. Global cognitive function in children with epilepsy: A community-based study. Epilepsia 2008, 49, 608-614. [CrossRef]

4. Weijenberg, A.; Brouwer, O.F.; Callenbach, P.M. Levetiracetam Monotherapy in Children with Epilepsy: A Systematic Review. CNS Drugs 2015, 29, 371-382. [CrossRef]

5. Lynch, B.A.; Lambeng, N.; Nocka, K.; Kensel-Hammes, P.; Bajjalieh, S.M.; Matagne, A.; Fuks, B. The synaptic vesicle protein SV2A is the binding site for the antiepileptic drug levetiracetam. Proc. Natl. Acad. Sci. USA 2004, 101, 9861-9866. [CrossRef]

6. Levisohn, P.M.; Mintz, M.; Hunter, S.J.; Yang, H.; Jones, J. Neurocognitive effects of adjunctive levetiracetam in children with partial-onset seizures: A randomized, double-blind, placebo-controlled, noninferiority trial. Epilepsia 2009, 50, 2377-2389. [CrossRef] [PubMed]

7. Fisher, R.S.; Acevedo, C.; Arzimanoglou, A.; Bogacz, A.; Cross, J.H.; Elger, C.E.; Engel, J., Jr.; Forsgren, L.; French, J.A.; Glynn, M.; et al. ILAE official report: A practical clinical definition of epilepsy. Epilepsia 2014, 55, 475-482. [CrossRef] [PubMed]

8. Fisher, R.S.; Cross, J.H.; French, J.A.; Higurashi, N.; Hirsch, E.; Jansen, F.E.; Lagae, L.; Moshé, S.L.; Peltola, J.; Roulet Perez, E.; et al. Operational classification of seizure types by the International League Against Epilepsy: Position Paper of the ILAE Commission for Classification and Terminology. Epilepsia 2017, 58, 522-530. [CrossRef] [PubMed]

9. Lhatoo, S.D.; Sander, J.W. The epidemiology of epilepsy and learning disability. Epilepsia 2001, 42, 6-9. [CrossRef]

10. Robertson, J.; Hatton, C.; Emerson, E.; Baines, S. Prevalence of epilepsy among people with intellectual disabilities: A systematic review. Seizure 2015, 29, 46-62. [CrossRef] [PubMed]

11. Doran, Z.; Shankar, R.; Keezer, M.R.; Dale, C.; McLean, B.; Kerr, M.P.; Devapriam, J.; Craig, J.; Sander, J.W. Managing anti-epileptic drug treatment in adult patients with intellectual disability: A serious conundrum. Eur. J. Neurol. 2016, 23, 1152-1157. [CrossRef]

12. Forsgren, L.; Edvinsson, S.O.; Blomquist, H.K.; Heijbel, J.; Sidenvall, R. Epilepsy in a population of mentally retarded children and adults. Epilepsy Res. 1990, 6, 234-248. [CrossRef]

13. Buelow, J.M.; Shore, C.P. Management challenges in children with both epilepsy and intellectual disability. Clin. Nurse Spec. CNS 2010, 24, 313-320. [CrossRef] [PubMed]

14. Ijff, D.M.; Aldenkamp, A.P. Cognitive side-effects of antiepileptic drugs in children. Handb Clin. Neurol. 2013, 111, 707-718. [CrossRef]

15. Loring, D.W.; Meador, K.J. Cognitive side effects of antiepileptic drugs in children. Neurology 2004, 62, 872-877. [CrossRef] [PubMed]

16. Pickrell, W.O.; Lacey, A.S.; Thomas, R.H.; Lyons, R.A.; Smith, P.E.; Rees, M.I. Trends in the first antiepileptic drug prescribed for epilepsy between 2000 and 2010. Seizure 2014, 23, 77-80. [CrossRef] [PubMed]

17. Ben-Menachem, E.; Gilland, E. Efficacy and tolerability of levetiracetam during 1-year follow-up in patients with refractory epilepsy. Seizure 2003, 12, 131-135. [CrossRef] 
18. Cortes, C.; Manterola, C. Behavioral alterations associated with levetiracetam in pediatric epilepsy. Epilepsy Behav. 2020, 112, 107472. [CrossRef] [PubMed]

19. Harden, C. Safety profile of levetiracetam. Epilepsia 2001, 42, 36-39. [CrossRef]

20. Glauser, T.A. Behavioral and psychiatric adverse events associated with antiepileptic drugs commonly used in pediatric patients. J. Child Neurol. 2004, 19, S25-S38. [CrossRef]

21. Szucs, A.; Clemens, Z.; Jakus, R.; Rásonyi, G.; Fabó, D.; Holló, A.; Barcs, G.; Kelemen, A.; Janszky, J. The risk of paradoxical levetiracetam effect is increased in mentally retarded patients. Epilepsia 2008, 49, 1174-1179. [CrossRef]

22. Zhou, S.; Zhan, Q.; Wu, X. Effect of Levetiracetam on Cognitive Function and Clonic Seizure Frequency in Children with Epilepsy. Curr. Mol. Med. 2019, 19, 699-703. [CrossRef] [PubMed]

23. Aldenkamp, A.; Besag, F.; Gobbi, G.; Caplan, R.; Dunn, D.W.; Sillanpää, M. Psychiatric and Behavioural Disorders in Children with Epilepsy (ILAE Task Force Report): Adverse cognitive and behavioural effects of antiepileptic drugs in children. Epileptic Disord. Int. Epilepsy J. Videotape 2016, 18, S55-S67. [CrossRef]

24. Brodtkorb, E.; Klees, T.M.; Nakken, K.O.; Lossius, R.; Johannessen, S.I. Levetiracetam in adult patients with and without learning disability: Focus on behavioral adverse effects. Epilepsy Behav. 2004, 5, 231-235. [CrossRef] [PubMed]

25. Tekgül, H.; Gencpinar, P.; Çavuşoğlu, D.; Dündar, N.O. The efficacy, tolerability and safety of levetiracetam therapy in a pediatric population. Seizure 2016, 36, 16-21. [CrossRef]

26. Lagae, L.; Buyse, G.; Ceulemans, B. Clinical experience with levetiracetam in childhood epilepsy: An add-on and mono-therapy trial. Seizure 2005, 14, 66-71. [CrossRef]

27. Gümüss, H.; Kumandaş, S.; Per, H. Levetiracetam monotherapy in newly diagnosed cryptogenic West syndrome. Pediatric Neurol. 2007, 37, 350-353. [CrossRef]

28. Li, J.; Xiao, N.; Chen, S. Efficacy and tolerability of levetiracetam in children with epilepsy. Brain Dev. 2011, 33, 145-151. [CrossRef]

29. Huber, B.; Bömmel, W.; Hauser, I.; Horstmann, V.; Liem, S.; May, T.; Meinert, T.; Robertson, E.; Schulz, L.; Seidel, M.; et al. Efficacy and tolerability of levetiracetam in patients with therapy-resistant epilepsy and learning disabilities. Seizure 2004, 13, 168-175. [CrossRef]

30. Peake, D.; Mordekar, S.; Gosalakkal, J.; Mukhtyar, B.; Buch, S.; Crane, J.; Wheway, R.; Rittey, C.; Donnelly, J.; Whitehouse, W.P.; et al. Retention rate of levetiracetam in children with intractable epilepsy at 1 year. Seizure 2007, 16, 185-189. [CrossRef]

31. Symonds, J.D.; Zuberi, S.M.; Johnson, M.R. Advances in epilepsy gene discovery and implications for epilepsy diagnosis and treatment. Curr. Opin. Neurol. 2017, 30, 193-199. [CrossRef] [PubMed]

32. Perucca, P.; Bahlo, M.; Berkovic, S.F. The Genetics of Epilepsy. Annu. Rev. Genom. Hum. Genet. 2020, 21, 205-230. [CrossRef] [PubMed]

33. Dilena, R.; Striano, P.; Traverso, M.; Viri, M.; Cristofori, G.; Tadini, L.; Barbieri, S.; Romeo, A.; Zara, F. Dramatic effect of levetiracetam in early-onset epileptic encephalopathy due to STXBP1 mutation. Brain Dev. 2016, 38, 128-131. [CrossRef] [PubMed]

34. Le Roux, M.; Barth, M.; Gueden, S.; Desbordes de Cepoy, P.; Aeby, A.; Vilain, C.; Hirsch, E.; de Saint Martin, A.; Portes, V.D.; Lesca, G.; et al. CACNA1A-associated epilepsy: Electroclinical findings and treatment response on seizures in 18 patients. Eur. J. Paediatr. Neurol. 2021, 33, 75-85. [CrossRef] [PubMed] 